\title{
Correspondence
}

\section{The Calman Report on specialist training}

Sir: My inclination is to side with Dr Kisely (Psychiatric Bulletin, May 1994, 18, 309) against the CTC's response to the Calman Report as expressed by Dr Davies (Psychiatric Bulletin, May 1994, 18, 308-309) and I would question whether the CTC view is really representative of trainees.

The College proposal to downgrade the registrar grade to SHO and to call the senior registrar grade the unified training grade (UTG) gives a clear message to trainees that they should carry on as before for less money. The Calman proposal to combine registrar and senior registrar grades could immediately abolish the postmembership registrar bottleneck, to the relief of trainees demoralised by the competition for senior registrar posts immediately after the trials of the MRCPsych examination.

Moreover, the Calman plans to shorten the length of training must benefit psychiatry because of the number of unfilled consultant posts. The College plans may make psychiatry less attractive compared to other specialities, at a time when there is some evidence that recruitment to psychiatry is falling.

Combining the SHO and registrar grade could make the period of general professional/basic specialist training too long. What are the entry requirements to UTG going to be and will there be a link with MRCPsych? How many SHOs and UTGs does the College think are needed?

Although the privileges of senior registrars have been hard-earned. I think we have got the balance between higher and junior trainees wrong. We should be protecting the less experienced trainees from taking on service reponsibilities. I can understand why senior registrars want to stay in their posts longer than they should before accepting the realities of consultant work but such a system does not help to fill vacant consultant posts and pull through the backlog of post-membership registrars.

My hope is that the CTC and other College committees will seriously consider whether psychiatric training can be further improved in the light of the Calman Report rather than following the President's "conservative" lead.

D.B. Double, Sheffield Postgraduate Psychiatric Education, Northern General Psychiatric Unit, Sheffield S5 7AU
Sir: I am sorry to say that Dr Double misrepresents "the College proposal" in relation to the Calman Report.

There has been no suggestion in any College document or statement that we should "down grade the registrar grade to SHO". All specialities will be required to move to two training grades within the timetable which is agreed.

Trainees in psychiatry will have the same terms and conditions of service as those in other specialities, and the grades will provide a structured training programme from registration to CCST as is required.

The terms and conditions of service of the two grades have not yet been discussed and there is no proposal of which I am aware that trainees should "carry on as before for less money"; why on earth should they?

We expect in the setting of numbers to be trained in the two grades to "immediately abolish the post membership registrar bottle-neck" and I should be grateful if $\mathrm{Dr}$ Double could indicate how, under his proposal, we would be able to identify those trainees who are suitable for higher specialist training in one of the six psychiatric specialities (and how would they?)

Our proposals under Calman will still involve specialist training which is shorter than that in many specialities, where the minimum length of higher specialist training will still be at least five years.

I should be interested in the criteria against which Dr Double is making the judgement that "the period of general professional/basic specialist training" is too long. That has not been the perception of any group of individuals within the College since the Calman proposals have been debated. Should we shorten the training deemed essential for specialist practice in psychiatry because we currently have a manpower problem (and moreover one that is not of our making)?

The entry requirements to the UTG will be agreed by the College and the JCHPT when the proposals for the grade have been decided between the profession and the NHSE, though I am sure that there will be a connection with the MRCPsych. (As I write the last meeting on the UTG working groups is about to occur).

In terms of planning the numbers of doctors required in each training grade, the College will continue to relate this to consultant opportunities but in any event the planning and monitoring of training grade numbers are currently being streamlined by the NHSE. 